\title{
Prognostic significance of aquaporins in human biliary tract carcinoma
}

\author{
SHINICHI SEKINE ${ }^{1}$, YUTAKA SHIMADA ${ }^{1}$, TAKUYA NAGATA ${ }^{1}$, MAKOTO MORIYAMA $^{1}$, \\ TETSUYA OMURA $^{1}$, TOMOKO WATANABE ${ }^{1}$, RYOUTA HORI ${ }^{1}$, ISAKU YOSHIOKA ${ }^{1}$, \\ TOMOYUKI OKUMURA ${ }^{1}$, SHIGEAKI SAWADA ${ }^{1}$, JUNYA FUKUOKA ${ }^{2}$ and KAZUHIRO TSUKADA ${ }^{1}$
}

Departments of ${ }^{1}$ Surgery and Science, ${ }^{2}$ Surgical Pathology, University of Toyama, Toyama, Toyama 930-0194, Japan

Received December 28, 2011; Accepted February 15, 2012

DOI: 10.3892/or.2012.1747

\begin{abstract}
Aquaporins (AQPs) are important in controlling bile formation, however, the exact role of AQPs in human biliary tract carcinogenesis has not been clearly defined. In this study, we analyzed AQP-1, $-4,-5$ and -8 expression immunohistochemically using tissue microarrays (TMAs) in 81 samples. (45 gallbladder carcinomas and 36 bile duct carcinomas). The survival of patients with high AQP-5 expression was longer compared to that of patients with low AQP-5 expression ( $\mathrm{P}=0.017)$. Cox's proportional hazard model revealed that AQP-5 expression was an independent prognostic factor $(\mathrm{RR}, 0.38 ; \mathrm{P}=0.025)$. Chi-square analysis revealed that high AQP-5 expression correlated to small tumor size in biliary tract carcinoma patients $(\mathrm{P}=0.006)$. With regard to the expression of other AQPs, depth of tumor invasion, histological type and serum carbohydrate antigen 19-9 (CA19-9) were associated with high AQP-1 expression $(\mathrm{P}=0.039,0.011$ and 0.032). However, AQP-4 and AQP-8 expression had no association with clinicopathological factors. Among the 10 patients who underwent gemcitabine (GEM) plus S-1 postoperative chemotherapy, the group of patients $(n=5)$ with high AQP-5 expression were associated with higher rates of both overall and disease-free survival (log-rank $\mathrm{P}=0.033,0.002$ ). In conclusion, the results of this study suggest that AQP-5 expression may be associated with prognosis and drug sensitivity in biliary tract carcinoma.
\end{abstract}

Correspondence to: Dr Shinichi Sekine, Department of Surgery and Science, University of Toyama, 2630 Sugitani, Toyama 930-0194, Japan

E-mail: sekky@med.u-toyama.ac.jp

Abbreviations: AQP, aquaporin; TMA, tissue microarray; RR, risk ratio; GEM, gemcitabine; UICC, Union for International Cancer Control; FFPE, formalin-fixed paraffin-embedded; H\&E, hematoxylin and eosin; CEA, carcinoembryonic antigen; CA19-9, carbohydrate antigen 19-9

Key words: aquaporin, biliary tract carcinoma, tissue microarray, immunohistochemistry

\section{Introduction}

Aquaporins (AQPs) are integral membrane proteins which facilitate the movement of water, and they are expressed in many kinds of cells, especially in polarized epithelial cells (1-3). AQPs are essential for bile water secretion and reabsorption. However, little is known about the function of AQPs water channels in human biliary tract carcinoma. At least 3 AQPs, AQP-1, -4 and -8, are known to be expressed in the biliary tract (4). AQP-1 and -4 are also implicated in the intrahepatic bile duct absorption of water (5). The epithelial cells of human and mouse gallbladder express AQP-1 and -8 (6,7). In the human gallbladder, AQP-1 is localized on both the apical and basolateral plasma membranes of epithelial cells lining the neck portion of the organ (6).

Recently, it seems that AQP has an important role in human carcinogenesis. We previously reported that AQP-5 may be involved in differentiation of human gastric carcinoma cells, and overexpression of several aquaporins has been reported in different types of human carcinoma (8-16). However, the role of AQPs in biliary tract carcinogenesis has not yet been clearly defined. Biliary tract carcinoma, consisting of gallbladder carcinoma and bile duct carcinoma, is a more lethal disease compared to other gastrointestinal cancers. The resection rate and the curative resection rate were 67.0-69.8\% and $30.4-37.7 \%$, respectively (17). The five-year survival rate after surgical resection was $41.6 \%$ for gallbladder carcinoma, and $33.1 \%$ for bile duct carcinoma (17). Surgical resection is the only chance for a cure, however, it is only applicable for selected patients. Thus, in order to understand the mechanisms in biliary tract carcinoma, we evaluated the role of AQPs on biliary tract carcinoma.

\section{Materials and methods}

Tissue samples. A series of surgical specimens from patients with biliary tract carcinoma were used. The patients with distant metastasis were excluded from the analysis. We used paraffin-embedded tissues of 81 samples (45 gallbladder carcinoma, 36 bile duct carcinoma) of the patients who underwent surgery from 1997 to 2010 at Toyama University Hospital, Japan. All samples were histologically diagnosed at the Department of Pathology. The final stage of biliary 
tract carcinoma was confirmed pathologically according to the TNM classification system of malignant tumors by the UICC, sixth edition.

Tissue microarray(TMA). TMAs are composed of small $1.0 \mathrm{~mm}$ cores of tissue from patient's paraffin blocks. The formalin-fixed paraffin-embedded (FFPE) blocks used throughout this study contained tumor tissue. For tissue stamping, the tumor areas were marked on H\&E-stained sections and marked directly on the corresponding FFPE blocks. Tissue cores were only obtained from tumor-bearing areas. Paraffin-embedded tumor material was cut into $4 \mu \mathrm{m}$-thick sections and placed onto glass slides. Slides were stained with $H \& E$ and examined for histopathology and tissue retention. The remaining sections were stored at room temperature until use (18).

Immunohistochemical staining. AQP-1, -4, -5 and -8 expression were analyzed by TMAs (Fig. 1A). The protein expressions of the AQPs were evaluated by the combination of the immunohistological intensity and distribution (18). The plot underwent a primary analysis and a secondary analysis. The average score were used for further study. The final decision was made by discussion of two researchers (S.S. and R.H.). Images of immunohistochemistry staining were photographed under a microscope, and digitized slide images were analyzed (Fig. 1A). Selected micrographs from the TMAs immunostained with polyclonal antibodies raised against AQP-1, -4, -5 and -8 are shown in Fig. 1B. The following primary antibodies were used: anti-AQP-1 (H-55; Santa Cruz Biotechnology, Inc.) antibodies were used at 1:100 dilution. Anti-AQP-4 (H-80) and anti-AQP-8 (H-85) antibodies (Santa Cruz Biotechnology, Inc.) were used at 1:200 dilution. Anti-AQP-5 (H-200; Santa Cruz Biotechnology, Inc.) antibodies were used at 1:50 dilution. The secondary antibodies used were goat anti-rabbit IgG-HRP according to the manufacturer's instructions. The staining intensity was scored as: 0 , no staining of carcinoma cells; 1 , weak staining; 2 , moderate staining; 3, marked staining. The staining distribution within the tumor cells was graded as: $0,<10 \% ; 1, \geq 10 \%-<50 \%$; and $2, \geq 50 \%$ ). Expression of AQPs in the carcinoma tissue was defined as positive when the sum total of the staining intensity and distribution was 3 or more (Fig. 1C). Polarization pattern were classified into two groups with polarized/mixed pattern or lost polarization pattern (Fig. 1D).

Postoperative chemotherapy. There were 17 patients who underwent postoperative chemotherapy after aggressive surgical resection. There were 11 cases of R0 (microscopically margin-negative resection specimen with no residual microscopic or macroscopic tumor in the resection bed) and 6 cases of R1 (macroscopic tumor clearance but microscopically, margins were positive for tumor). As first-line chemotherapy, 7 patients received fluoropyrimidine $(\mathrm{S}-1)$ or fluorouracil chemotherapy, and 10 cases received gemcitabine (GEM) plus fluoropyrimidine (S-1) chemotherapy (GS). We analyzed the relationship between AQP expression and prognosis of the 10 patients who received GS treatment (19-21).

Statistical analysis. The statistical evaluation was done by Chi-square test and t-test. Prognostic factors were examined
Table I. Patient characteristics.

\begin{tabular}{lcc}
\hline Terms & $\mathrm{N}$ & $(\%)$ \\
\hline Age (years) & & \\
$\quad<70$ years & 36 & 44.4 \\
$\geq 70$ years & 45 & 55.6 \\
Gender & & \\
Female & 46 & 56.8 \\
Male & 35 & 43.2 \\
Organ & & \\
Gallbladder & 45 & 55.6 \\
Bile duct & 36 & 44.4 \\
Tumor size $(\mathrm{cm})$ & & \\
$<2$ & 16 & 80.2 \\
$\geq 2$ & 65 &
\end{tabular}

Depth of tumor invasion

T1-T2

T3-T4

Lymph node metastasis

Negative

60.5

Positive

Histrogical type

Pap/well/moderate

Poor/others

Lymphovascular invasion

Negative

46.2

Positive

53.8

Vascular invasion

Negative $\quad 38$

Positive

Serum tumor markers

CEA (ng/ml)

$>5$

CA19-9 (U/ml)

$\leq 37$

58.2

$>37$

46

41.8

Postoperative chemotherapy

Yes

40.7

No

48 59.3

by both univariate and multivariate analyses. Survival curves were estimated using the Kaplan-Meier method, and differences between survival curves were analyzed using the log-rank test. Multivariate analyses were produced using the Cox's proportional hazards model to test the risk of cancer death. The Chi-square model was used for analysis of the factors relating to AQP. All statistical analyses were considered significant 


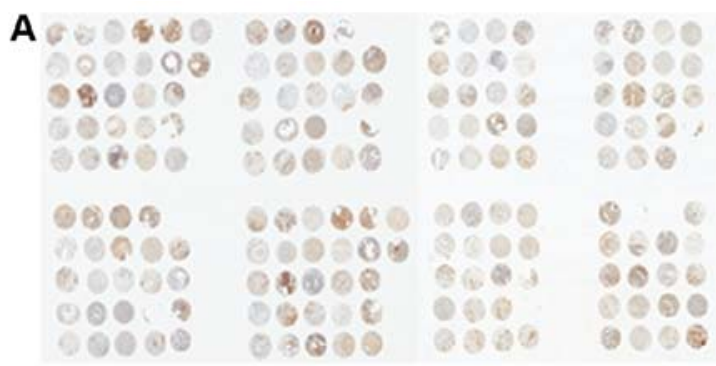

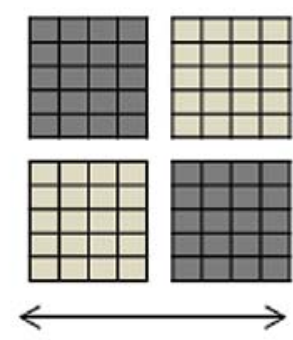

Gallbladder carcinoma

C

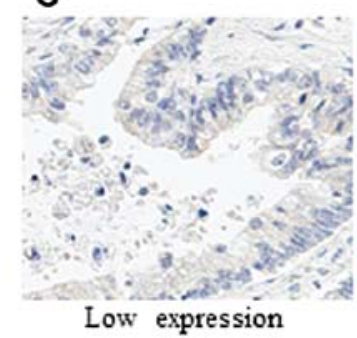

Low expression
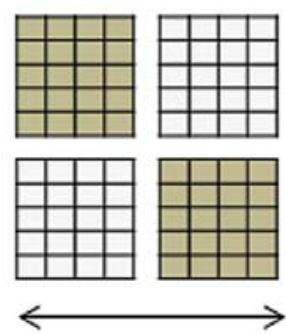

Bile duct carcinoma

B
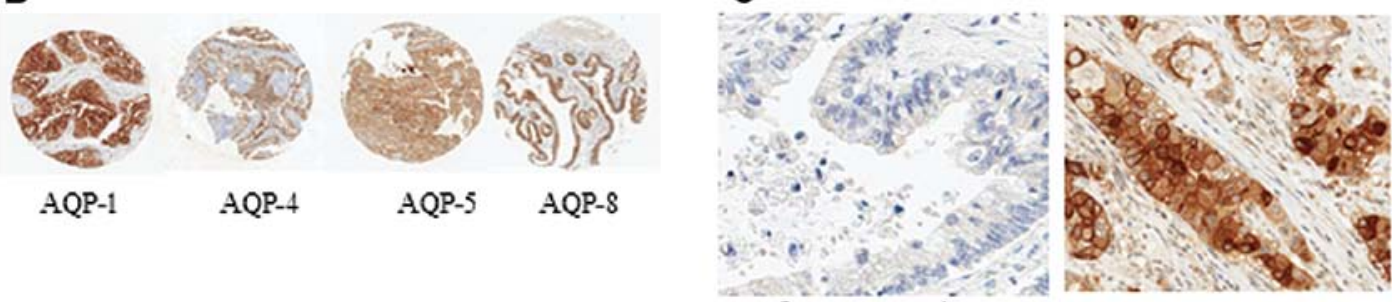

High expression

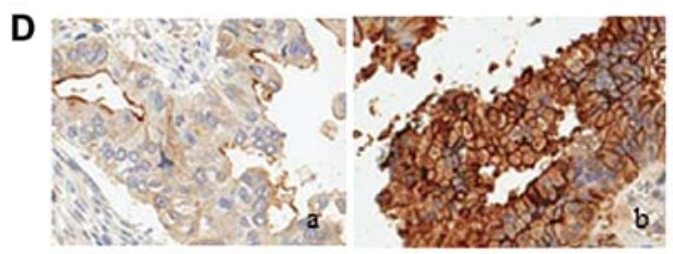

Figure 1. (A) Immunohistochemistry of AQP-5 by tissue microarray (TMA). The plot was analyzed in duplicate. (B) Images of immunohistochemistry staining AQP-1, -4, -5 and -8 in gallbladder carcinoma. (C) AQP-5 expression in bile duct carcinoma. Staining intensity and distribution ranging from 0 to 2 is low expression (left). Scale of 3 to 5 is high expression (right). (D) Expression of AQP-5 in gallbladder carcinoma. (Da) Apical expression, and (Db) loss of polarization pattern.

Table II. The expression of AQP-1, $-4,-5$ and -8 in the biliary tract carcinoma.

\begin{tabular}{lcccc}
\hline & AQP-1(+) & AQP-4(+) & AQP-5(+) & AQP-8(+) \\
\hline Gallbladder & $23 / 44$ & $9 / 45$ & $25 / 43$ & $12 / 43$ \\
$(\%)$ & $(52.3)$ & $(20.0)$ & $(58.1)$ & $(27.9)$ \\
Bile duct & $4 / 36$ & $25 / 36$ & $2 / 36$ \\
$(\%)$ & $(45.7)$ & $(11.1)$ & $(69.4)$ & $(5.6)$ \\
Total & 136 & $49 / 79$ & $14 / 79$ \\
$(\%)$ & $(47 / 80$ & $(16.0)$ & $(63.2)$ & $(17.2)$ \\
\hline
\end{tabular}

at a P-value of 0.05 . Statistical analyses were performed by Windows (SAS Institute Inc., NC).

\section{Results}

The expression of $A Q P-1,-4,-5$ and -8 protein in biliary tract carcinoma tissues. The clinicopathological backgrounds of the patients are shown in Table I. Table II shows the AQP expression positivity in the bile duct and gallbladder carcinoma tissue. AQP-4 and -8 were more highly expressed in gallbladder carcinoma than in bile duct carcinoma. AQP-1 and -5 expression ratio was similar in the case of the two organs. Of the two, AQP-5 had the higher positivity. In the 49 high AQP-5 expression cases, loss of the subcellular polarization pattern was detected in 29 cases (Fig. 1D). The rate of AQP-1 was
22/36, AQP-4 was 7/13, and all the 14 high AQP-8 expression were loss of polarization pattern.

Prognostic impact of AQP expression. Depth of tumor invasion, lymph node metastasis, TMN stage, tumor size $(\geq 2.0)$, histological type, vascular invasion, carcinoembryonic antigen (CEA) $(\geq 5)$, and CA19-9 ( $\geq 37)$ were associated with survival $(\mathrm{P}<0.001,0.006,<0.001,0.035,0.002,0.001,<0.001$ and 0.019 , respectively) (Table III). Survival of the patients with high AQP-5 expression was significantly longer than that of the patients in the low AQP-5 expression group $(\mathrm{P}=0.017)$. Other AQPs, AQP-1, -4 and -8 had no significant impact on survival (Fig. 2). Furthermore, Cox's proportional hazard model revealed that AQP-5 expression was an independent prognostic factor $(\mathrm{RR}, 0.34 ; \mathrm{P}=0.012)$. Depth of tumor invasion 

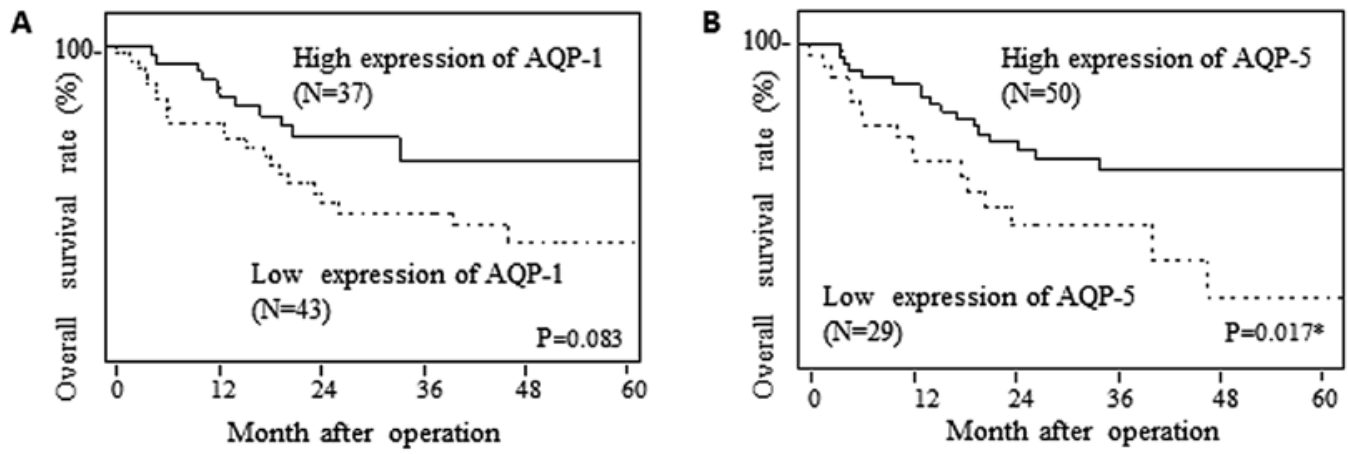

Figure 2. Survival rates of biliary tract carcinoma patients. (A) AQP-1. (B) AQP-5. Kaplan-Meier analysis reveals a significantly less favorable overall survival rate in patients with AQP-5 high expression compared with low AQP-5 expression (log-rank test, $\mathrm{P}=0.017$ ).

Table III. Relationship between patient characteristics and prognosis in biliary tract carcinoma. Univariate and multivariate analyses.

\begin{tabular}{|c|c|c|c|c|}
\hline \multirow[b]{2}{*}{ Terms } & \multirow{2}{*}{$\frac{\text { Univariate analysis }}{\text { P-value }}$} & \multicolumn{3}{|c|}{ Multivariate analysis } \\
\hline & & Risk ratio & $95 \% \mathrm{CI}$ & P-value \\
\hline Age ( $\geq 70$ years) & 0.648 & 1.317 & $(0.579-3.053)$ & 0.512 \\
\hline Gender (male) & 0.818 & 1.665 & $(0.660-4.210)$ & 0.278 \\
\hline Depth of tumor invasion (T1/T2) & $<0.001^{\mathrm{a}}$ & 0.296 & $(0.089-0.906)$ & $0.033^{\mathrm{b}}$ \\
\hline Lymph node metastasis (present) & $0.006^{\mathrm{a}}$ & 1.171 & $(0.406-3.305)$ & 0.767 \\
\hline Tumor size $(\geq 2)$ & $0.035^{\mathrm{b}}$ & 0.948 & $(0.251-4.776)$ & 0.942 \\
\hline Histological type (pap/well/moderate) & $0.002^{\mathrm{a}}$ & 0.394 & $(0.151-1.064)$ & 0.066 \\
\hline Lymphovascular invasion (present) & 0.512 & & & \\
\hline Vascular invasion (present) & $0.001^{\mathrm{a}}$ & 2.096 & $(0.788-5.910)$ & 0.139 \\
\hline $\mathrm{CEA}>5(\mathrm{ng} / \mathrm{ml})$ & $<0.001^{\mathrm{a}}$ & 7.172 & $(2.896-18.181)$ & $<0.001^{\mathrm{a}}$ \\
\hline CA19-9 $>37(\mathrm{U} / \mathrm{ml})$ & $0.019^{\mathrm{b}}$ & 0.865 & $(0.339-2.183)$ & 0.759 \\
\hline Postoperative chemotherapy (yes) & 0.639 & & & \\
\hline AQP-1 expression (positive) & 0.083 & & & \\
\hline AQP-4 expression (positive) & 0.171 & & & \\
\hline AQP-5 expression (positive) & $0.022^{\mathrm{b}}$ & 0.382 & $(0.161-0.884)$ & $0.025^{\mathrm{b}}$ \\
\hline AQP-8 expression (positive) & 0.359 & & & \\
\hline
\end{tabular}

Cox's proportional hazard model revealed that AQP-5 expression was an independent prognostic factor (RR, 0.382; $\mathrm{P}=0.025)$. Depth of tumor invasion and CEA $>5 \mathrm{U} / \mathrm{ml}$ were associated with survival in multivariate analysis. ${ }^{a} \mathrm{P}<0.01 ;{ }^{b} \mathrm{P}<0.05$.

(RR, 0.26; $\mathrm{P}=0.011)$ and CEA $(\mathrm{RR}, 7.62 ; \mathrm{P}<0.001)$ were also associated with survival in multivariate analysis (Table III).

Analysis between AQP-1 and -5 expression and various prognostic factors. We found that depth of tumor invasion and histological type were associated with AQP-1 expression $(\mathrm{P}=0.021$ and 0.014$)$. AQP-5 expression was significantly associated with tumor size $(\mathrm{P}=0.006)$ by Chi-square analysis No other relationship was observed between the clinicopathological characteristics of the patients and AQP-5 expression (Table IV). There was no relationship between high AQP-1 expression and high AQP-5 expression $(\mathrm{P}=0.178)$ (data not shown). Multivariate logistic models revealed that there were no significant predictors for AQP-1 and -5 expression.

Relationship between the AQP-5 expression and the response to postoperative chemotherapy. As first-line chemotherapy,
7 patients received fluoropyrimidine (S-1) or fluorouracil chemotherapy, and 10 cases received gemcitabine (GEM) plus fluoropyrimidine (S-1) chemotherapy (GS). Table V shows prognosis of biliary tract carcinoma patients who received GEM plus S-1 postoperative chemotherapy. Patients with high AQP-5 expression had significantly more favorable rate of both (Fig. 3A) overall and (Fig. 3B) disease-free survival compared to patients with low AQP-5 expression (Fig. 3) (logrank test; $\mathrm{P}=0.033$ and 0.002 ).

\section{Discussion}

The results of the study show that AQP-5 had the most important role in prognosis of biliary tract carcinoma among AQP-1, -4, -5 and -8 . The multivariate proportional hazards model revealed that high AQP-5 expression was an independent and favorable prognostic factor. The results of this study differ from previous 
Table IV. Relationship between patient characteristics and AQP-1 and AQP-5 in biliary tract carcinoma.

\begin{tabular}{|c|c|c|c|c|c|c|}
\hline \multirow[b]{2}{*}{ Terms } & \multicolumn{3}{|c|}{ AQP-1 expression } & \multicolumn{3}{|c|}{ AQP-5 expression } \\
\hline & $\begin{array}{l}\text { Positive } \\
(\mathrm{n}=37)\end{array}$ & $\begin{array}{c}\text { Negative } \\
(n=43)\end{array}$ & P-value & $\begin{array}{c}\text { Positive } \\
(\mathrm{n}=50)\end{array}$ & $\begin{array}{c}\text { Negative } \\
(n=29)\end{array}$ & P-value \\
\hline \multicolumn{7}{|l|}{ Age (years) } \\
\hline$<70$ & 13 & 23 & 0.099 & 25 & 10 & 0.178 \\
\hline$\geq 70$ & 24 & 20 & & 25 & 19 & \\
\hline \multicolumn{7}{|l|}{ Gender } \\
\hline Female & 25 & 21 & 0.090 & 28 & 17 & 0.821 \\
\hline Male & 12 & 22 & & 22 & 12 & \\
\hline \multicolumn{7}{|c|}{ Depth of tumor invasion } \\
\hline $\mathrm{T} 1-\mathrm{T} 2$ & 24 & 18 & $0.039^{\mathrm{a}}$ & 27 & 14 & 0.624 \\
\hline T3-T4 & 13 & 25 & & 23 & 15 & \\
\hline \multicolumn{7}{|c|}{ Lymph node metastasis } \\
\hline Absent & 23 & 25 & 0.714 & 31 & 16 & 0.552 \\
\hline Present & 14 & 18 & & 19 & 13 & \\
\hline \multicolumn{7}{|l|}{ TNM stage } \\
\hline $\mathrm{I} / \mathrm{II}$ & 27 & 24 & 0.109 & 35 & 15 & 0.106 \\
\hline III & 10 & 19 & & 15 & 14 & \\
\hline \multicolumn{7}{|l|}{ Tumor size } \\
\hline$<2$ & 9 & 6 & 0.256 & 13 & 1 & $0.006^{b}$ \\
\hline$\geq 2$ & 28 & 36 & & 37 & 27 & \\
\hline \multicolumn{7}{|l|}{ Histological type } \\
\hline Pap/well/moderate & 34 & 30 & $0.011^{\mathrm{a}}$ & 43 & 20 & 0.272 \\
\hline Poor/others & 3 & 13 & & 7 & 9 & \\
\hline \multicolumn{7}{|c|}{ Lymphovascular invasion } \\
\hline Absent & 13 & 23 & 0.122 & 22 & 14 & 0.074 \\
\hline Present & 22 & 19 & & 27 & 14 & \\
\hline \multicolumn{7}{|l|}{ Vascular invasion } \\
\hline Absent & 20 & 18 & 0.307 & 25 & 12 & 0.437 \\
\hline Present & 16 & 23 & & 23 & 16 & \\
\hline \multicolumn{7}{|l|}{ CEA (ng/ml) } \\
\hline$<5$ & 28 & 30 & 0.800 & 39 & 18 & 0.145 \\
\hline$\geq 5$ & 9 & 11 & & 10 & 10 & \\
\hline \multicolumn{7}{|l|}{ CA19-9 (U/ml) } \\
\hline$<37$ & 26 & 19 & $0.032^{\mathrm{a}}$ & 31 & 13 & 0.152 \\
\hline$\geq 37$ & 11 & 22 & & 18 & 15 & \\
\hline \multicolumn{7}{|c|}{ Postoperative chemotherapy } \\
\hline Yes & 15 & 17 & 0.927 & 18 & 14 & 0.285 \\
\hline No & 22 & 26 & & 32 & 15 & \\
\hline
\end{tabular}

${ }^{\mathrm{a}} \mathrm{P}<0.05 ;{ }^{\text {b }} \mathrm{P}<0.01$.

studies in colorectal and non-small cell lung cancers $(12,22)$. AQP-5 induced cell proliferation via Ras/ERK/Rb pathway in colorectal cancer $(22,23)$, and it promoted tumor invasion in nonsmall cell lung cancer (12). Overexpression of AQP-5 increased proliferation and migration in colorectal and non-small cell lung carcinoma. The results of this study suggested that AQP-5 may play a different role in biliary tract carcinoma, such as facilitation of bile transport and reabsorption. The roles of biliary epithelium were different from those of the colon and of the lung (24).

With regard to the AQP-5 protein distribution (25-29), the expression of AQP-5 in human ovarian tissues was reported to be mainly localized in the basolateral membrane of benign 
Table V. Postoperative chemotherapy patients (GEM plus S-1).

\begin{tabular}{|c|c|c|c|c|c|c|c|c|c|c|}
\hline No. & Organ & Gender & $\begin{array}{c}\text { Age } \\
\text { (years) }\end{array}$ & $\begin{array}{l}\text { UICC } \\
\text { stage }\end{array}$ & $\begin{array}{c}\text { AQP-5 } \\
\text { expression }\end{array}$ & $\begin{array}{l}\text { Survival time } \\
\text { (months) }\end{array}$ & Prognosis & $\begin{array}{l}\text { Recurrence } \\
\text { (months) }\end{array}$ & $\begin{array}{c}\text { Cause of } \\
\text { death }\end{array}$ & $\begin{array}{l}\text { Postoperative } \\
\text { chemotherapy }\end{array}$ \\
\hline 1 & $\mathrm{BD}$ & $\mathrm{F}$ & 72 & $2 \mathrm{a}$ & Positive & 26.5 & DF & $(-)$ & & $\mathrm{GEM}+\mathrm{S}-1$ \\
\hline 2 & $\mathrm{BD}$ & $\mathrm{F}$ & 62 & 3 & Positive & 26.9 & DF & $(-)$ & & $\mathrm{GEM}+\mathrm{S}-1$ \\
\hline 3 & $\mathrm{BD}$ & $\mathrm{F}$ & 64 & 3 & Positive & 16.0 & DF & $(-)$ & & GEM+S-1 \\
\hline 4 & $\mathrm{BD}$ & M & 58 & $1 b$ & Positive & 51.7 & DF & $(-)$ & & GEM+S-1 \\
\hline 5 & BD & M & 79 & $1 b$ & Positive & 32.9 & DF & $(-)$ & & GEM+S-1 \\
\hline 6 & GB & $\mathrm{F}$ & 63 & 3 & Negative & 12.8 & Dead & 5.4 & Liver metastasis & GEM+S-1 \\
\hline 7 & $\mathrm{BD}$ & $\mathrm{F}$ & 63 & 3 & Negative & 8.7 & Reccurence (liver) & 3.9 & & GEM+S-1 \\
\hline 8 & $\mathrm{BD}$ & $\mathrm{F}$ & 80 & $2 b$ & Negative & 26.7 & Reccurence (liver) & 20.7 & & GEM+S-1 \\
\hline 9 & $\mathrm{BD}$ & M & 51 & 3 & Negative & 16.2 & Dead & 6.2 & Bone metastasis & GEM+S-1 \\
\hline 10 & $\mathrm{BD}$ & M & 69 & $1 b$ & Negative & 7.2 & Dead & 2.2 & $\begin{array}{l}\text { Peritoneal } \\
\text { dissemination }\end{array}$ & $\mathrm{GEM}+\mathrm{S}-1$ \\
\hline
\end{tabular}
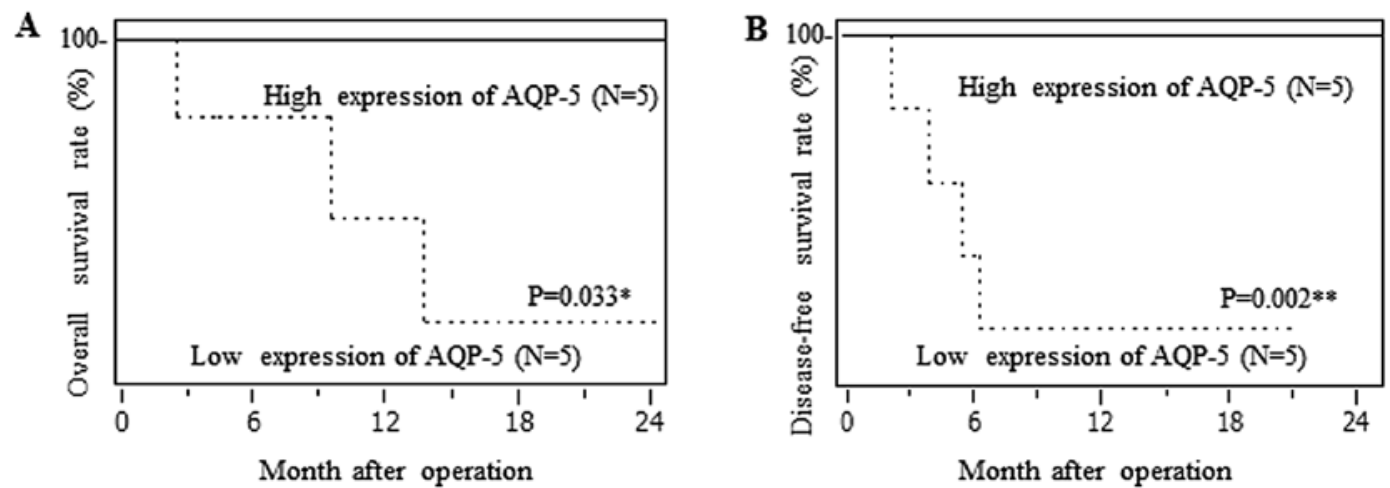

Figure 3. Survival rates of biliary tract carcinoma patients who received GEM plus S-1 postoperative chemotherapy. Kaplan-Meier analysis reveals a significantly less favorable (A) overall and (B) disease-free survival rate in patients without AQP-5 expression compared with those with AQP-5 expression (log-rank test, $\mathrm{P}=0.033,0.002)$. ${ }^{*} \mathrm{P}<0.05 ;{ }^{* * *} \mathrm{P}<0.01$.

tumor cells and apical and basolateral membranes of borderline cells, or scattered in the membrane of malignant cells, and absent in the normal epithelium (30). The results of our study were consistant with this report and AQP-5 expression was mixed or lost polarization and scattered in the membrane in more than half of the patients. AQP-1, -4 and -8 also show similar features. The expression of AQP-5 was associated with small tumor size in biliary tract cancer. This phenomenon was also observed in colon carcinoma $(9,16)$. However, AQP expression was maintained through the late stage of colon carcinoma. These results suggested that AQP-5 was included in early-stage disease and might represent a functional ability of bile transfer channel in biliary tract carcinoma.

Not only AQP-5 but also AQP-1 expression were correlated with clinicopathological factors. Similar AQP-1 and -5 expression patterns were observed in pancreatic carcinoma (31). Furthermore, negative AQP-1 expression was an independent prognostic factor in intrahepatic cholangiocarcinoma (32). Thus, AQP-1 also have some role in hepatobiliary and pancreatic carcinoma.

With regard to chemotherapy for biliary tract carcinoma, gemcitabine (GEM) and S-1 are commonly used. Although our study size was small, high AQP-5 expression showed an inverse association $(\mathrm{P}=0.011)$ with postoperative recurrence. The data suggested that expression of AQP-5 may play an important role in drug sensitivity. AQPs may be attractive targets for the development of novel drug therapies for disorders that involve aberrant water movement (33-36). However discovery of additional roles of AQPs is necessary.

In conclusion, this study shows that AQP-5 is highly expressed in biliary tract carcinoma. High AQP-5 expression was associated with small tumor size and favorable prognosis of biliary tract carcinoma patients. Our result suggest that AQPs expression demonstrates prognosis and drug sensitivity in biliary tract carcinoma. Further study of AQPs would contribute to the clinically treatment for biliary tract cancer.

\section{Acknowledgements}

We thank Mr. Mikuni Nemoto for technical support. This study was supported by KAKENHI Grant-in-Aid for Scientific Research (C) from the Ministry of Education, Culture, Sports, Science and Technology of Japan. 


\section{References}

1. Verkman AS and Mitra AK: Structure and function of aquaporin water channels. Am J Physiol Renal Physiol 278: F13-F28, 2000

2. Brown D, Katsura T, Kawashima M, et al: Cellular distribution of the aquaporins: a family of water channel proteins. Histochem Cell Biol 104: 1-9, 1995.

3. Mobasheri A and Marples D: Expression of the AQP-1 water channel in normal human tissues: a semiquantitative study using tissue microarray technology. Am J Physiol Cell Physiol 286: C529-C537, 2004.

4. Portincasa P, Palasciano G, Svelto M, et al: Aquaporins in the hepatobiliary tract. Which, where and what they do in health and disease. Eur J Clin Invest 38: 1-10, 2008.

5. Masyuk AI, Gong AY, Kip S, et al: Perfused rat intrahepatic bile ducts secrete and absorb water, solute, and ions. Gastroenterology 119: 1672-1680, 2000

6. Nielsen S, Smith BL, Christensen EI, et al: Distribution of the aquaporin CHIP in secretory and resorptive epithelia and capillary endothelia. Proc Natl Acad Sci USA 90: 7275-7279, 1993.

7. Calamita G, Ferri D, Bazzini C, et al: Expression and subcellular localization of the AQP8 and AQP1 water channels in the mouse gall-bladder epithelium. Biol Cell 97: 415-423, 2005.

8. Watanabe T, Fujii T, Oya T, et al: Involvement of aquaporin-5 in differentiation of human gastric cancer cells. J Physiol Sci 59: 113-122, 2009

9. Woo J, Lee J, Chae YK, et al: Overexpression of AQP5, a putative oncogene, promotes cell growth and transformation. Cancer Let 264: 54-62, 2008.

10. Zhang ZQ, Zhu ZX, Bai CX, et al: Aquaporin 5 expression increases mucin production in lung adenocarcinoma. Oncol Rep 25: 1645-1650, 2011

11. Mazal PR, Susani M, Wrba F, et al: Diagnostic significance of aquaporin-1 in liver tumors. Hum Pathol 36: 1226-1231, 2005.

12. Chae YK, Woo J, Kim MJ, et al: Expression of aquaporin 5 (AQP5) promotes tumor invasion in human non small cell lung cancer. PLoS One 3: e2162, 2008.

13. Zhang Z, Chen Z, Song Y, et al: Expression of aquaporin 5 increases proliferation and metastasis potential of lung cancer. J Pathol 221: 210-220, 2010.

14. Shen L, Zhu Z, Huang Y, et al: Expression profile of multiple aquaporins in human gastric carcinoma and its clinical significance. Biomed Pharmacother 64: 313-318, 2010

15. Mobasheri A, Airley R, Hewitt SM, et al: Heterogeneous expression of the aquaporin 1 (AQP1) water channel in tumors of the prostate, breast, ovary, colon and lung: a study using high density multiple human tumor tissue microarrays. Int J Oncol 26: $1149-1158,2005$

16. Moon C, Soria JC, Jang SJ, et al: Involvement of aquaporins in colorectal carcinogenesis. Oncogene 22: 6699-6703, 2003.

17. Miyakawa S, Ishihara S, Horiguchi A, et al: Biliary tract cancer treatment: 5,584 results from the Biliary Tract Cancer Statistics Registry from 1998 to 2004 in Japan. J Hepatobiliary Pancreat Surg 16: 1-7, 2009.

18. Fukuoka J, Fujii T, Shih JH, et al: Chromatin remodeling factors and BRM/BRG1 expression as prognostic indicators in non-small cell lung cancer. Clin Cancer Res 10: 4314-4324, 2004.
19. Murakami Y, Uemura K, Sudo T, et al: Adjuvant gemcitabine plus S-1 chemotherapy improves survival after aggressive surgical resection for advanced biliary carcinoma. Ann Surg 250: 950-956, 2009.

20. Skipworth JR, Olde Damink SW, Imber C, et al: Review article: surgical, neo-adjuvant and adjuvant management strategies in biliary tract cancer. Aliment Pharmacol Ther 34: 1063-1078, 2011.

21. Park HS, Lim JY, Yoon DS, et al: Outcome of adjuvant therapy for gallbladder cancer. Oncology 79: 168-173, 2010.

22. Kang SK, Chae YK, Woo J, et al: Role of human aquaporin 5 in colorectal carcinogenesis. Am J Pathol 173: 518-525, 2008.

23. Woo J, Lee J, Kim MS, et al: The effect of aquaporin 5 overexpression on the Ras signaling pathway. Biochem Biophys Res Commun 367: 291-298, 2008.

24. Machida Y, Ueda Y, Shimasaki M, et al: Relationship of aquaporin 1,3 , and 5 expression in lung cancer cells to cellular differentiation, invasive growth, and metastasis potential. Hum Pathol 42: 669-678, 2011.

25. Ma T, Song Y, Gillespie A, et al: Defective secretion of saliva in transgenic mice lacking aquaporin-5 water channels. J Biol Chem 274: 20071-20074, 1999.

26. Krane CM, Melvin JE, Nguyen HV, et al: Salivary acinar cells from aquaporin 5-deficient mice have decreased membrane water permeability and altered cell volume regulation. J Biol Chem 276: 23413-23420, 2001.

27. Song Y and Verkman AS: Aquaporin-5 dependent fluid secretion in airway submucosal glands. J Biol Chem 276: 41288-41292, 2001.

28. Matsuzaki T, Tajika Y, Suzuki T, et al: Immunolocalization of the water channel, aquaporin-5 (AQP5), in the rat digestive system. Arch Histol Cytol 66: 307-315, 2003.

29. Matsuzaki T, Tajika Y, Ablimit A, et al: Aquaporins in the digestive system. Med Electron Microsc 37: 71-80, 2004.

30. Yang JH, Shi YF, Cheng Q, et al: Expression and localization of aquaporin-5 in the epithelial ovarian tumors. Gynecol Oncol 100: 294-299, 2006.

31. Burghardt B, Elkaer ML, Kwon TH, et al: Distribution of aquaporin water channels AQP1 and AQP5 in the ductal system of the human pancreas. Gut 52: 1008-1016, 2003.

32. Aishima S, Kuroda Y, Nishihara Y, et al: Down-regulation of aquaporin-1 in intrahepatic cholangiocarcinoma is related to tumor progression and mucin expression. Hum Pathol 38: 1819-1825, 2007.

33. Wang F, Feng XC, Li YM, et al: Aquaporins as potential drug targets. Acta Pharmacol Sin 27: 395-401, 2006.

34. Jeyaseelan K, Sepramaniam S, Armugam A, et al: Aquaporins: a promising target for drug development. Expert Opin Ther Targets 10: 889-909, 2006

35. Saadoun S,Papadopoulos MC,Hara-Chikuma M, et al: Impairment of angiogenesis and cell migration by targeted aquaporin-1 gene disruption. Nature 434: 786-792, 2005.

36. Verkman AS: More than just water channels: unexpected cellular roles of aquaporins. J Cell Sci 118: 3225-3232, 2005. 